Original Article

\title{
BUTT AND HIT - THE HEART KIDNEY SAGA: A SNAP SHOT AND LONG TERM PERSPECTIVES
}

\author{
Raghava Sharma ${ }^{1} \&$ Shashank Shetty ${ }^{2}$ \\ ${ }^{1}$ Professor, ${ }^{2}$ Sr Resident, Dept of Medicine, \\ K.S. Hegde M edical Academy, NITTE University, Deralakatte, M angalore - 575018. \\ Currespondence : \\ Raghava Sharma, \\ Professor, Department of M edicine \\ K.S. Hegde Medical Acadamy, NITTE University, Deralakatte, Mangalore- 575018. \\ Mobile : +91 9448770919 E-mail : rrsharma1967@yahoo.com
}

\begin{abstract}
:
Tobacco smoking is an universal problem. There are about 120 million smokers in India in the age group of 30-69 years and have an increased cardiovascular and renal risks in addition to other risks attributable to smoking.

The present study was aimed to assess the cardiovascular and renal risks especially among the young smokers in the age group of 20-40 years. After all necessary administrative and ethical clearances a cross sectional study was conducted at the tertiary care medical college hospital located at $M$ angalore. 75 young male smokers in the age group of 20-40 years along with equal number of age, sex matched non smokers as controls were recruited and each one were assessed for Blood pressure(BP), Electro cardiographic changes(ECG changes), and Glomerular filtration rate(GFR).

In the present study Smoking resulted in high systolic blood pressure and prolonged QT interval (QTC) as compared to the non smokers, thus increasing the risk of Sudden cardiac death among smokers. Longer duration of smoking of more than 10 years resulted in Pre hypertension and reduced GFR in comparison to smokers with lesser duration of smoking of less than 10 years.

This study highlights the need to tackle "Smoking" among young adults more aggressively to avoid the potential cardiovascular and renal complications, as Tobacco smoking is a major modifiable risk factor for the same.
\end{abstract}

Keywords: Tobacco smoking, Young adults, Cardiovascular and renal risks, Sudden cardiac death, QT interval, Glomerular filtration rate (GFR).

\section{Introduction:}

Tobacco smoking is an universal problem and a malady more so among young adults. Tobacco use in different population groups is reported to have a prevalence of $15 \%$ to over $50 \%$ among men ${ }^{1}$. Large household surveys in recent years have shown that there are about 120 million smokers in India, of whom $37 \%$ are all men and $5 \%$ are all women in the age group of 30-69 years. Smoking may soon account for $20 \%$ of all male deaths and $5 \%$ of all female

\begin{tabular}{|c|}
\hline Access this article online \\
\hline Quick Response Code \\
\hline
\end{tabular}

deaths among Indians in the age group of $30-69$ years $^{1}$

More than 4000 compounds have been identified in the tobacco smoke. This complex mixture of chemical substances has unique pro inflammatory and cyto toxic effects ${ }^{2}$

IIl effects of smoking (Nicotine) on cardiovascular and renal systems can be attributed to the following mechanisms:

I Smoking (Nicotine) exerts effect on the proximal tubule and renal haemo dynamics resulting in increased GFR, sodium chloride excretion, and urine flow ${ }^{3.4}$.

I Smoking(Nicotine) causes marked attenuation of alpha and beta adrenergic blockade, prolonged increase in plasma norepinephrine and epinephrine, thus leading to a marked and prolonged increase in heart rate and blood pressure ${ }^{5}$

I Smoking (Nicotine) accelerates atherosclerotic process by its pro sclerotic and pro thrombotic effects.

I Smoking (Nicotine) has an unfavorable influence on autonomic balance leading to QT prolongation and 
prolonged QTc with a lowered ventricular threshold and occurrence of sudden cardiac death ${ }^{6}$.

\section{Materials and Methods:}

The present cross sectional study conducted at the tertiary care medical college hospital at Mangalore, coastal Karnataka comprised of 75 young male smokers in the age group of 20-40 years, who smoked more than 10 cigarettes per day for more than 5 years. Age and sex matched controls were also drawn. Females, hypertensives, diabetics, patients with known renal diseases, patients taking drugs that affect QT interval and patients taking drugs affecting GFR were excluded from the study.

After obtaining written informed consent from each participant a detailed history with particular emphasis on duration and number of cigarettes smoked was sought and a thorough clinical examination was performed. Blood pressure (BP) was recorded from the right arm in sitting posture using mercury sphygmomanometer by a single person (to avoid inter personal variability). An average of two BP readings taken five minutes apart was considered for analysis. Blood sample for creatinine estimation was drawn soon after BP measurement and GFR was calculated using creatinine clearance rate using the cockroftt gault formula.

$$
\mathrm{Ccr}=\frac{(140-\text { Age }) X \text { weight }[\mathrm{kg}]}{\mathrm{Cr}[\mathrm{mg} / \mathrm{dl}] \times 72}
$$

Electro cardiograph (ECG) was obtained at the same time and analyzed for any abnormalities in terms of rate, rhythm, axis deviation, chamber hypertrophy, ischaemia, and QT prolongation.

Chi square test was employed for analysis of observations and conclusions were drawn from the same.

\section{Observationsand Results:}

*In the present study, mean age of smokers was 31.27 years while it was the same 31.78 years for the non smoker control group also (Table 1).
*M aximum smokers belonged to the age group of 26-30 years (Table 2).

* Raised systolic BP in the pre hypertension range of 121 $130 \mathrm{mmHg}$ was noted in the $61.2 \%$ of smokers as compared to $38.8 \%$ among non smokers. (Table 3 , Fig 1). Out of this $65.2 \%$ had a smoking history of more than 10 years while $28.8 \%$ had less than 10 years of smoking history, thus demonstrating a clear statistically significant $(P<0.0001)$ correlation between smoking, duration of smoking and raised systolic BP (Table 4, Fig 2) There was no significant correlation with respect to diastolic BP between smokers and non smokers and with respect to duration of smoking.( Table 5, Fig 3).

* QTC interval was significantly prolonged in smokers as compared to non smokers, which was statistically significant with $\mathrm{P}<0.05$. However no correlation was found in relation to the duration of smoking. (Table 6 , Fig 4).

*GFR decreased with increased duration of smoking ( $>10$ years ) as compared to lesser duration of smoking ( $<10$ years ), which was statistically significant with $P=0.042$. However there was no statistically significant difference of GFR between smokers and non smokers. (Table $7 \& 8$, Fig $5 \& 6)$.

\section{Discussion :}

Effect of smoking on cardiovascular and renal system is very vital and forms a long term perspective particularly among young adults. The present study being unique has addressed this issue by involving young adults in the age group of 20-40 years only.

Wang et $\mathrm{al}^{7}$ had observed that young smokers were at higher risk of developing cardiovascular risks as compared to older adults. Study by Paola et $\mathrm{al}^{8}$ on older men demonstrated a higher systolic BP among smokers as compared to non smokers ( 144 mmhg Vs 140 mmhg ), but with no such differences in diastolic BP among the two groups. However our study conducted on young men also confirms the same, which was statistically significant too ( $P$ $<0.05)$. 
Study by Okubo et al ${ }^{9}$ found lesser systolic BP in light to moderate smokers as compared to non smokers (121 mmhg Vs $123 \mathrm{mmhg}$ ). However Our study contradicts the above findings as higher percentage of smokers were in the Pre hypertension range (defined as systolic BP of 121-139 mmhg or diastolic BP of 81-89 mmhg by JNC 7) compared to non smokers and systolic hypertension was evident in smokers with prolonged duration of smoking ( $>10$ years ) as compared to lesser duration of smoking ( $<10$ years). The above findings of our study may be attributed to chronic smoking induced atherogenesis in large capacitance vessels which is easily amenable to correction by modifying the risk factor of smoking.

Study by Mehmet illeri et al $^{6,9}$ demonstrated smoking predisposes to prolongation of QT interval and QTC dispersion, thus increasing the risk of sudden cardiac death in them due to lowered ventricular fibrillation threshold and pro arrhythmic effect of catecholamine and nor epinephrine spillover. Our present study reconfirms the same and was statistically significant too with $\mathrm{P}<0.05$.

Halimi et $\mathrm{al}^{10}$ in his study on the effects of smoking on renal function concluded that creatinine clearance was higher in smokers as compared to non smokers $(100.6 \mathrm{ml} / \mathrm{min}$ Vs $98.8 \mathrm{ml} / \mathrm{min}$ ) and the glomerular hyper filtration was associated with increased intra glomerular pressure and proteinuria. Our present study also confirmed a higher GFR among smokers compared to non smokers but was not statistically significant $(P>0.05)$.

\section{Conclusions:}

From the present study we conclude the following:

I Smoking predisposes to pre hypertension, systolic hypertension and prolonged QT interval among young smokers as compared to age, sex matched non smokers, thus increasing their risk to develop overt hypertension and associated cardiovascular complications including sudden cardiac death.

I Prolonged duration of smoking (> 10 years) results in GFR reduction and raised systolic blood pressure, thus increasing the risk of long term cardiovascular complications and also long term deterioration of renal functions among young smokers.

I Young smokers form an important risk group who require to be "COUNCELLED TO QUIT SMOKING" to prevent long term smoking induced cardiovascular and renal risks. THIS GOES A LONG WAY IN ACHIEVING A POLLUTION FREE ENVIRONMENT AND ALSO A PRODUCTIVE, HEALTHY YOUNG POPULATION AND SOCIETY.

Table1. Baseline characteristics between smokers and non-smokers.

\begin{tabular}{|l|c|c|c|}
\hline & Smokers & $\begin{array}{c}\text { Non } \\
\text { smokers } \\
\text { (mean) }\end{array}$ & P value \\
(mean)
\end{tabular}

Table 2: Age distribution between smokers and non smokers.

\begin{tabular}{|c|c|c|c|c|}
\hline & \multicolumn{2}{|c|}{ Smoker / NonSmoker } & \multirow[t]{2}{*}{ Total } \\
\hline & & Nonsmoker & Smoker & \\
\hline \multicolumn{5}{|c|}{ Age Group } \\
\hline \multirow[t]{2}{*}{$20-25$} & \multirow{2}{*}{$\begin{array}{l}\text { Count } \\
\% \text { within Age Group }\end{array}$} & 2 & 3 & 5 \\
\hline & & $40.0 \%$ & $60.0 \%$ & $100.0 \%$ \\
\hline \multirow[t]{2}{*}{$26-30$} & \multirow{2}{*}{$\begin{array}{l}\text { Count } \\
\% \text { within Age Group }\end{array}$} & 33 & 35 & 68 \\
\hline & & $48.5 \%$ & $51.5 \%$ & $100.0 \%$ \\
\hline \multirow[t]{2}{*}{$31-35$} & \multirow{2}{*}{$\begin{array}{l}\text { Count } \\
\% \text { within Age Group }\end{array}$} & 21 & 19 & 40 \\
\hline & & $52.5 \%$ & $47.5 \%$ & $100.0 \%$ \\
\hline \multirow[t]{2}{*}{$36-40$} & \multirow{2}{*}{$\begin{array}{l}\text { Count } \\
\% \text { within Age Group }\end{array}$} & 19 & 18 & 37 \\
\hline & & $51.4 \%$ & $48.6 \%$ & $100.0 \%$ \\
\hline \multirow[t]{2}{*}{ Total } & Count & 75 & 75 & 150 \\
\hline & \% within Age Group & $50.0 \%$ & $50.0 \%$ & $100.0 \%$ \\
\hline
\end{tabular}

$X^{2}=0.386, p=0.943$ 
Table 3 : Systolic Blood pressure distribution between the two groups.

\begin{tabular}{|c|c|c|c|c|c|}
\hline & \multicolumn{2}{|c|}{ Smoker / Non Smoker } & \multirow[t]{2}{*}{ Total } \\
\hline & & & Nonsmoker & Smoker & \\
\hline \multicolumn{6}{|c|}{ SBP group } \\
\hline & \multirow[t]{2}{*}{$100-110$} & \multirow{2}{*}{$\begin{array}{l}\text { Count } \\
\% \text { within SBP group }\end{array}$} & 27 & 11 & 38 \\
\hline & & & $71.1 \%$ & $28.9 \%$ & $100.0 \%$ \\
\hline & \multirow[t]{2}{*}{$111-120$} & \multirow{2}{*}{$\begin{array}{l}\text { Count } \\
\% \text { within SBP group }\end{array}$} & 28 & 20 & 48 \\
\hline & & & $58.3 \%$ & $41.7 \%$ & $100.0 \%$ \\
\hline & \multirow[t]{2}{*}{$121-130$} & \multirow{2}{*}{$\begin{array}{l}\text { Count } \\
\% \text { within SBP group }\end{array}$} & 19 & 30 & 49 \\
\hline & & & $38.8 \%$ & $61.2 \%$ & $100.0 \%$ \\
\hline & \multirow{2}{*}{$131-140$} & \multirow{2}{*}{$\begin{array}{l}\text { Count } \\
\% \text { within SBP group }\end{array}$} & 1 & 12 & 13 \\
\hline & & & $7.7 \%$ & $92.3 \%$ & $100.0 \%$ \\
\hline & \multirow[t]{2}{*}{$>140$} & \multirow{2}{*}{$\begin{array}{l}\text { Count } \\
\% \text { within SBP group }\end{array}$} & 0 & 2 & 2 \\
\hline & & & $.0 \%$ & $100.0 \%$ & $100.0 \%$ \\
\hline \multirow[t]{2}{*}{ Total } & Count & 75 & 75 & 150 & \\
\hline & & \% within SBP group & $50.0 \%$ & $50.0 \%$ & $100.0 \%$ \\
\hline
\end{tabular}

$X^{2}=21.847, p=0.0001$

TABLE 4 :Comparison between SBP and Duration of smoking.

\begin{tabular}{|c|c|c|c|c|c|}
\hline & \multicolumn{2}{|c|}{ duration of smoking group } & \multirow[t]{2}{*}{ Total } \\
\hline & & & $<10$ years & $>10$ years & \\
\hline \multirow[t]{15}{*}{ SBP group } & \multirow[t]{3}{*}{$100-110$} & \multirow{3}{*}{$\begin{array}{l}\text { Count } \\
\% \text { within SBP group } \\
\% \text { within duration of smoking group }\end{array}$} & 9 & 2 & 11 \\
\hline & & & $81.8 \%$ & $18.2 \%$ & $100.0 \%$ \\
\hline & & & $17.3 \%$ & $8.7 \%$ & $14.7 \%$ \\
\hline & \multirow[t]{3}{*}{$111-120$} & \multirow{3}{*}{$\begin{array}{l}\text { Count } \\
\% \text { within SBP group } \\
\% \text { within duration of smoking group }\end{array}$} & 19 & 1 & 20 \\
\hline & & & $95.0 \%$ & $5.0 \%$ & $100.0 \%$ \\
\hline & & & $36.5 \%$ & $4.3 \%$ & $26.7 \%$ \\
\hline & \multirow[t]{3}{*}{$121-130$} & \multirow{3}{*}{$\begin{array}{l}\text { Count } \\
\% \text { within SBP group } \\
\% \text { within duration of smoking group }\end{array}$} & 15 & 15 & 30 \\
\hline & & & $50.0 \%$ & $50.0 \%$ & $100.0 \%$ \\
\hline & & & $28.8 \%$ & $65.2 \%$ & $40.0 \%$ \\
\hline & \multirow[t]{3}{*}{$131-140$} & \multirow{3}{*}{$\begin{array}{l}\text { Count } \\
\% \text { within SBP group } \\
\% \text { within duration of smoking group }\end{array}$} & 7 & 5 & 12 \\
\hline & & & $58.3 \%$ & $41.7 \%$ & $100.0 \%$ \\
\hline & & & $13.5 \%$ & $21.7 \%$ & $16.0 \%$ \\
\hline & \multirow[t]{3}{*}{$>140$} & \multirow{3}{*}{$\begin{array}{l}\text { Count } \\
\% \text { within SBP group } \\
\% \text { within duration of smoking group }\end{array}$} & 2 & 0 & 2 \\
\hline & & & $100.0 \%$ & $.0 \%$ & $100.0 \%$ \\
\hline & & & $3.8 \%$ & $.0 \%$ & $2.7 \%$ \\
\hline \multirow[t]{2}{*}{ Total } & & Count & 52 & 23 & 75 \\
\hline & & $\%$ within SBP group & $69.3 \%$ & $30.7 \%$ & $100.0 \%$ \\
\hline
\end{tabular}

$X^{2}=13.844, p=0.008$

TABLE 5.Diastolic Blood pressure distribution between smokers and non smokers.

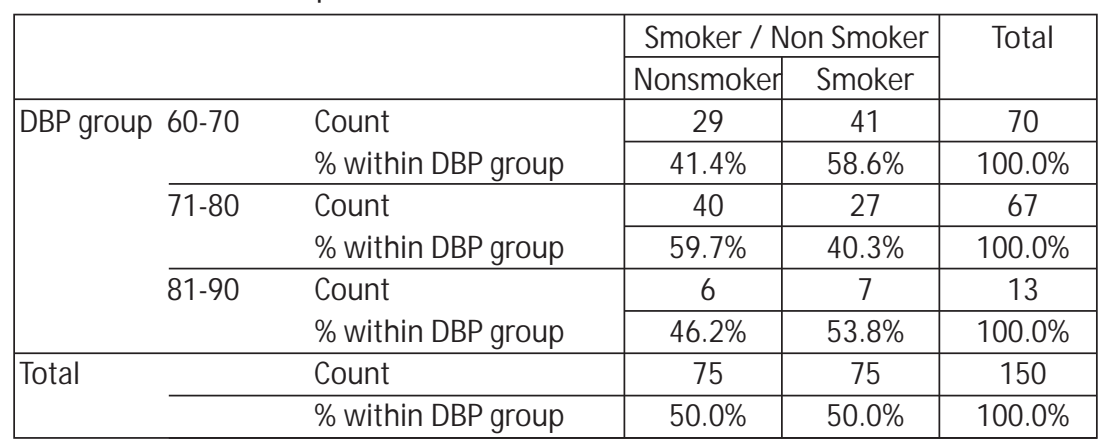

$X^{2}=4.656, p=0.097$ 
Table 6: QTc between smokers and non smokers

\begin{tabular}{|c|c|c|c|c|c|}
\hline & \multicolumn{2}{|c|}{ Smoker / Non Smoker } & \multirow[t]{2}{*}{ Total } \\
\hline & & & Nonsmoker & Smoker & \\
\hline \multirow[t]{4}{*}{ QTcgroup } & \multirow[t]{2}{*}{$<444$} & \multirow{2}{*}{$\begin{array}{l}\text { Count } \\
\% \text { within QTcgroup }\end{array}$} & 74 & 68 & 142 \\
\hline & & & $52.1 \%$ & $47.9 \%$ & $100.0 \%$ \\
\hline & \multirow[t]{2}{*}{$>444$} & \multirow{2}{*}{$\begin{array}{l}\text { Count } \\
\% \text { within QTcgroup }\end{array}$} & 1 & 7 & 8 \\
\hline & & & $12.5 \%$ & $87.5 \%$ & $100.0 \%$ \\
\hline \multirow[t]{2}{*}{ Total } & \multirow{2}{*}{\multicolumn{2}{|c|}{$\begin{array}{l}\text { Count } 75 \\
\% \text { within } \text { QTcgroup }\end{array}$}} & 75 & 150 & \\
\hline & & & $50.0 \%$ & $50.0 \%$ & $100.0 \%$ \\
\hline
\end{tabular}

$X^{2}=4.754, p=0.029$

Table 7 :GFR between smokers and non smokers

\begin{tabular}{|c|c|c|c|c|c|}
\hline & \multicolumn{2}{|c|}{ Smoker / Non Smoker } & \multirow[t]{2}{*}{ Total } \\
\hline & & & Nonsmoker & Smoker & \\
\hline \multirow[t]{8}{*}{ GFRgroup } & \multirow[t]{2}{*}{$60-75$} & \multirow{2}{*}{$\begin{array}{l}\text { Count } \\
\% \text { within GFRgroup }\end{array}$} & 17 & 15 & 32 \\
\hline & & & $53.1 \%$ & $46.9 \%$ & $100.0 \%$ \\
\hline & \multirow[t]{2}{*}{ 76- 90} & \multirow{2}{*}{$\begin{array}{l}\text { Count } \\
\% \text { within GFRgroup }\end{array}$} & 37 & 33 & 70 \\
\hline & & & $52.9 \%$ & $47.1 \%$ & $100.0 \%$ \\
\hline & \multirow[t]{2}{*}{$91-105$} & \multirow{2}{*}{$\begin{array}{l}\text { Count } \\
\% \text { within GFRgroup }\end{array}$} & 14 & 22 & 36 \\
\hline & & & $38.9 \%$ & $61.1 \%$ & $100.0 \%$ \\
\hline & \multirow[t]{2}{*}{$106-120$} & \multirow{2}{*}{$\begin{array}{l}\text { Count } \\
\% \text { within GFRgroup }\end{array}$} & 7 & 5 & 12 \\
\hline & & & $58.3 \%$ & $41.7 \%$ & $100.0 \%$ \\
\hline \multirow[t]{2}{*}{ Total } & & Count & 75 & 75 & 150 \\
\hline & & $\%$ within GFRgroup & $50.0 \%$ & $50.0 \%$ & $100.0 \%$ \\
\hline
\end{tabular}

$X^{2}=2.465, p=0.482$

Table8:Comparison of GFR with duration of smoking

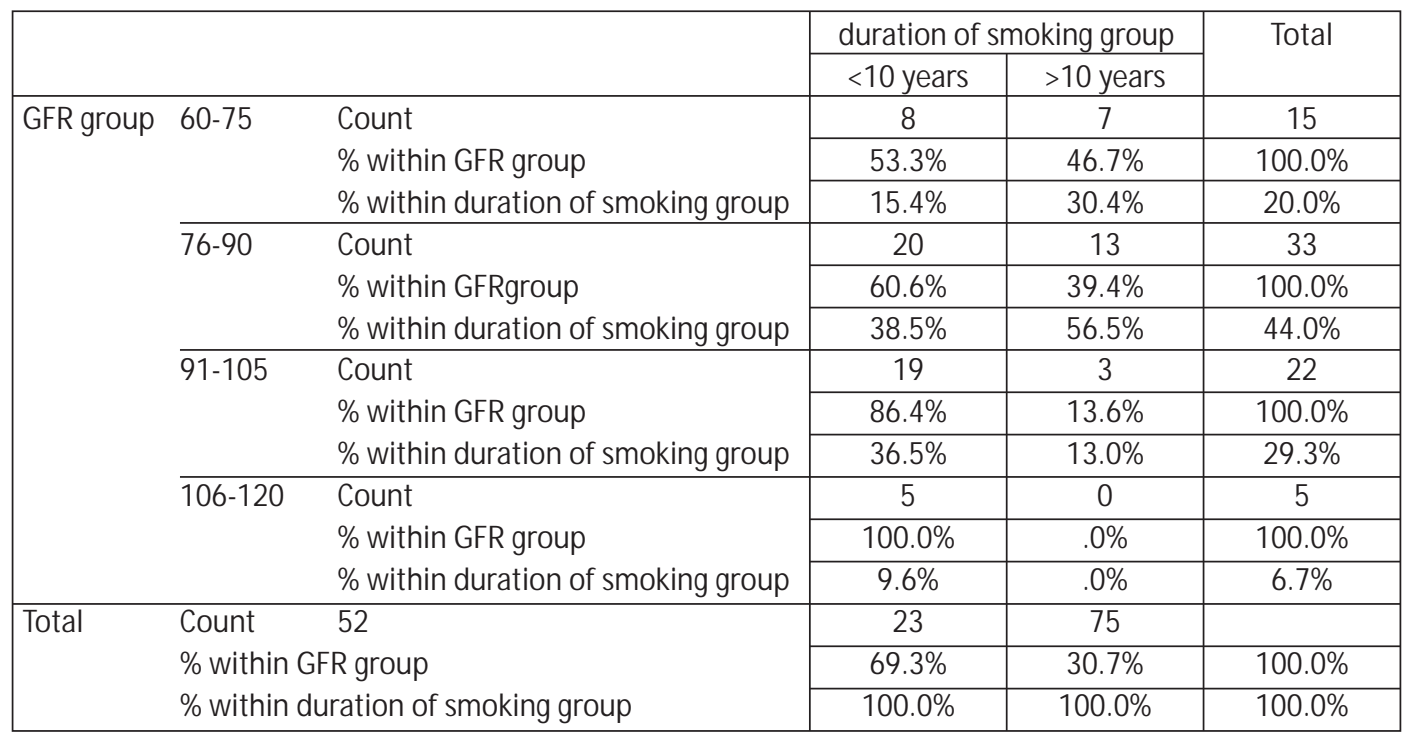

$X^{2}=8.201, p=0.042$ 
Figure 1.

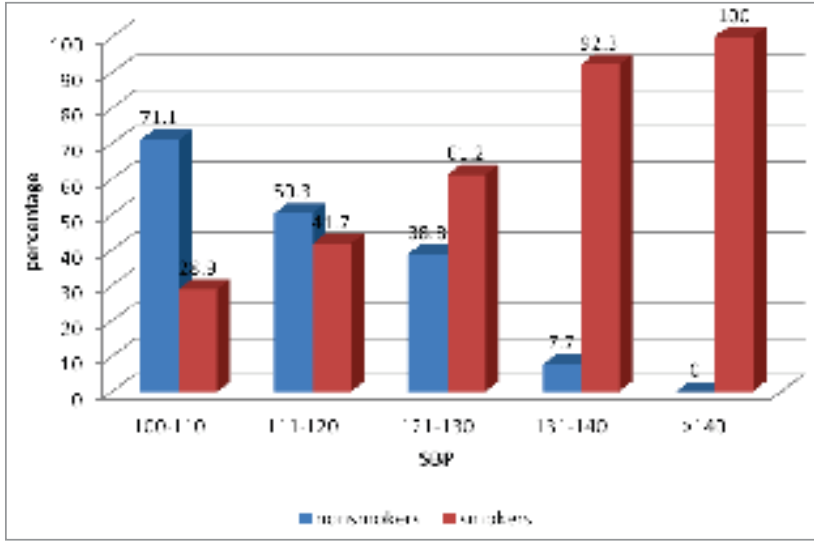

Higher percentage of young smokers in the pre-hypertension range as compared to age matched non smokers (61.2 \% VS $38.8 \%)$.

Figure 3.

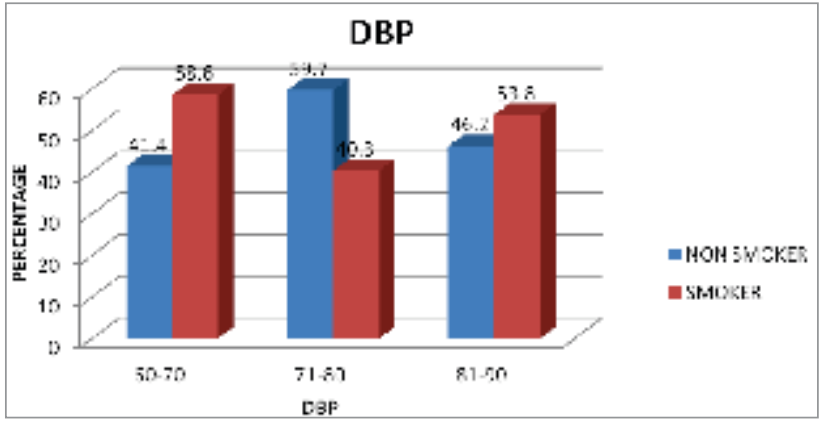

Diastolic Blood pressure between the two groups comparable but not statistically significant.

Figure 5.

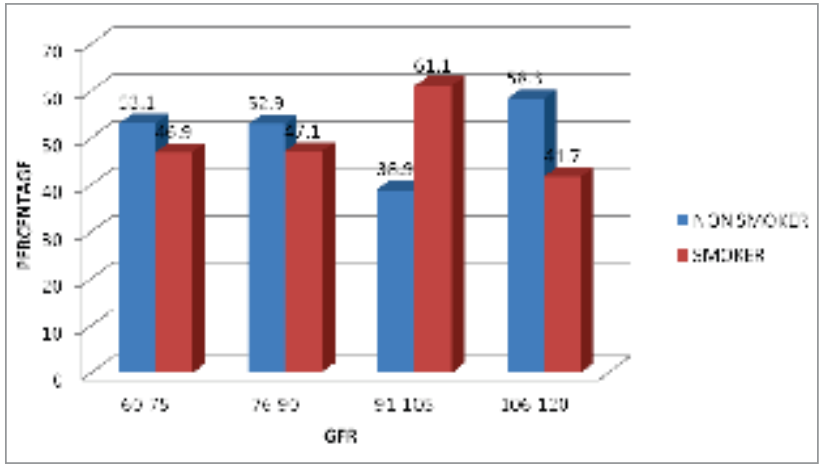

GFR between smokers and non smokers comparable but not statistically significant.
Figure 2.

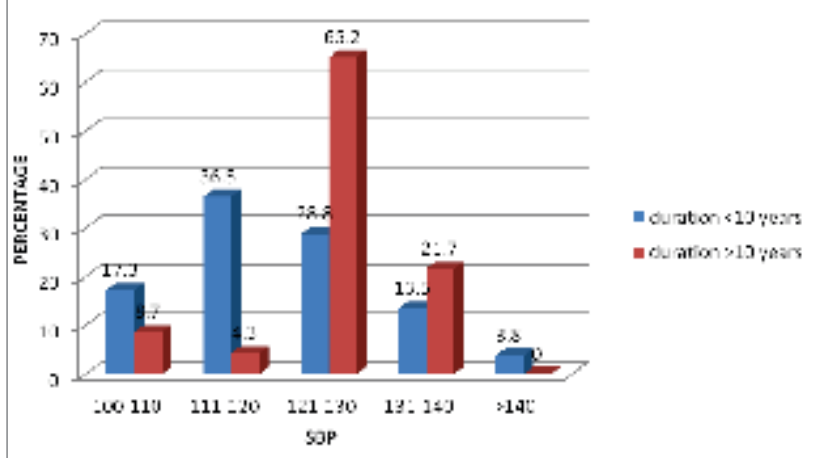

SBP (pre hypertensive range) significantly higher among smokers with smoking duration more than 10 years.

Figure 4.

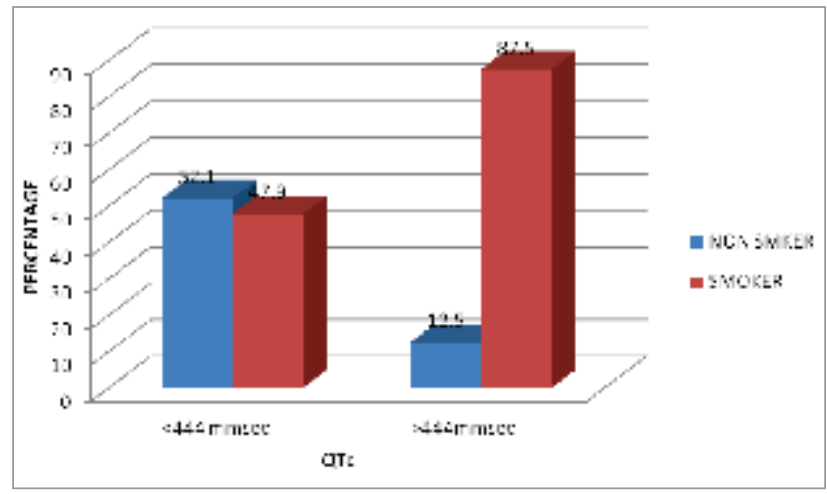

QTc in smokers significantly higher than non smokers.

Figure 6.

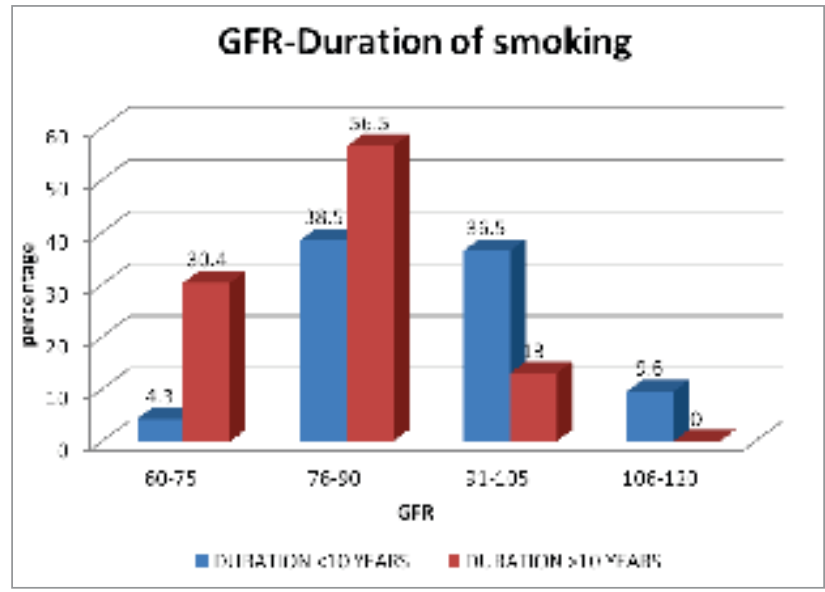

GFR reduction significantly higher with prolonged duration (>10years) of smoking. 


\section{References:}

1. Rani M, Bonu S, Jha P, Nguyen SN, Jam joum L. Tobacco use in India : Prevalence and predictors of smoking and chewing in a national cross sectional household survey. Tobacco control 2003; 12(4).

2. Rustemeier K, Stabbert R, Haussman HJ. Evaluation of the potential effects of ingredients added to cigarettes. Part 2: chemical composition of main stream smoke. Food chem. Toxicol 2002; 40 : 93 104

3. Orth SR. The renal risks of smoking. Kidney international.1997:51 ; 1669-1677

4. Orth SR, Hiroaki O, Eberhard R, Smoking and kidney. Nephro Dial and transplant. 2000; 15 : 1509-1511

5. Guido Grassi, Gino Seravalle, David A Calhoun, Gianni B Bolla, Cristina Giannattasio, Monica Marabini, et al Mechanisms responsible for sympathetic activation by cigarette smoking in humans. Circulation $1994,90: 248-253$
6. M ehmet Ileri, Ertan Yetkin, Izzet Tandogan, Ismet Hisar, Ramazan Atak Kubilay Senen et al. Effect of habitual smoking on QT interval and dispersion. American journal of cardiology 2001 : 88 ; 322-325

7. Wang $\mathrm{H}$, Shi $\mathrm{H}$, Wang $\mathrm{Z}$. Nicotine depresses the function of multiple cardiac potassium channels. Life Sci ; 1999: 65 ; 143-149

8. Poala Primatesta, Emanuel Falaschetti, Sunjay Gupta. Association between smoking and blood pressure. Hypertension $2001 ; 37$ : 187 193

9. Yokubo, T Miyamoto, Ysuwazono. An association between smoking habits and blood pressure in normotensive Japanese men. Journal of human hypertension. 2002;16:91-96

10. Jean Michel Halimi, Bruno Giraudeau, Sylviane Vol, Emile Caces, Hubert Nivet, Yvon Lebranchu and Jean Tichet. Effects of current smoking and smoking discontinuation on renal function and proteinuria in the general population. Kidney international $2000 ; 58$ 1285-1292 